This is a post-refereeing final draft. When citing, please refer to the published version:

Cohen, S.A., Duncan, T. \& Thulemark, M. (2013). Lifestyle mobilities: The crossroads of travel, leisure and migration. Mobilities, DOI: 10.1080/17450101.2013.826481

\title{
Lifestyle mobilities: The crossroads of travel, leisure and migration
}

Dr Scott A. Cohen

School of Hospitality and Tourism Management, University of Surrey, Guildford, UK

Dr Tara Duncan

Department of Tourism, University of Otago, Dunedin, New Zealand

Maria Thulemark

School of Technology and Business Studies, Dalarna University, Borlänge, Sweden

\begin{abstract}
This article examines how the mobilities paradigm intersects with physically moving as an on-going lifestyle choice. We conceptualise a lens of 'lifestyle mobilities' that challenges discrete notions of, and allows for a wider grasp of the increasing fluidity between travel, leisure and migration. We demonstrate how contemporary lifestyle-led mobility patterns contribute to and illustrate a breakdown in conventional binary divides between work and leisure, and a destabilisation of concepts of 'home' and 'away'. We unpack issues of identity construction, belonging and place attachment associated with sustained corporeal mobility, and conclude by suggesting avenues for the further study of lifestyle mobilities.
\end{abstract}

Keywords: lifestyle, corporeal, mobility, identity, belonging 


\section{Introduction}

Corporeal mobility is increasingly influenced by and through transnational ties, changing socio-cultural outlooks and technologies of transport, communication and social connectivity that characterise a (re)formation of the everyday. Whilst mobility itself is not a new idea in the social sciences (Cresswell 2010a), the idea of a mobilities 'paradigm' (Sheller and Urry 2006) or 'turn' (Hannam, Sheller and Urry 2006) has gained considerable speed over the last decade. Concomitantly, there has been a renewed focus and importance placed on ideas surrounding 'lifestyle' within the social sciences. In his analysis of why corporeal - that is physical, embodied - travel is increasing, despite communication advances that facilitate virtual and imaginative mobilities, Urry (2002, p. 256) highlights that "'being on the move" has become a "way of life" for many'. Thus corporeal mobility has become central to many lifestyle choices, with the patterns of such mobilities becoming more dynamic and complex than in the past as individuals use mobility choices to negotiate the growing complexity of modern living (McIntyre 2006).

Sheller and Urry (2006) note the challenge in adopting theories to 'keep up' with the ever changing and pervasive nature of new forms of (im)mobility. For some people, albeit still dominated by those in developed countries and elites in developing countries (Hall 2005), travel and mobility are increasingly everyday practices (Edensor 2007, Hannam 2008). The present conceptual paper introduces and explores how the mobilities paradigm intersects with physically moving as an on-going lifestyle choice. We engage an interdisciplinary approach in offering the term 'lifestyle mobilities' as a theoretical lens to challenge current thinking on the intersections between travel, leisure and migration (see also McIntyre 2009). Our aim is to contribute to mobilities studies by showing how voluntary on-going mobile lifestyles: 1) blur the boundaries between travel, leisure and migration; 2) are exemplary of 
how a binary divide between work and leisure may be collapsed; 3) destabilise dichotomies of 'home' and 'away'; and 4) illustrate complexities of belonging and identity associated with sustained mobility. This analysis is important not only for foregrounding patterns of lifestyle mobility positioned at the borders of travel, leisure and migration, but also for demonstrating how these mobility choices contribute to, and are emblematic of, continuing processes of dedifferentiation in contemporary social life (Bauman 2000, Cohen and Cohen 2012, Edensor 2007).

Although research on lifestyle migration (e.g. Benson 2011, Benson and O’Reilly 2009a), which often addresses more permanent and seasonal forms of lifestyle-led relocation, is the most closely associated body of research to explore the intersections of lifestyle, migration and mobility, it does not fully grasp the complexities of time and space found in more varied and multi-transitional manifestations of lifestyle mobility, as we discuss below. We thus hope to offer a deeper and wider understanding of the interrelations of travel, leisure and migration through a lens of lifestyle mobilities. In doing so, we highlight examples that illustrate these social patterns, before concluding with suggested directions for the further study of lifestyle mobilities.

\section{Lifestyles of mobility}

Previous attempts at defining lifestyle have typically concentrated on identifying lifestyles through patterns of everyday tangible behaviour. Sobel (1981, p. 3) thus defined lifestyle as 'any distinctive, and therefore recognisable, mode of living'. In addition to shared patterns of behaviour, Stebbins (1997) advocates that lifestyles encompass related sets of values and attitudes. Lifestyles can hence be seen as comprised of on-going tangible practices, orientations and ways of identifying, constituting 'the basis for a separate, common social 
identity' (ibid, p. 350). Consequently, lifestyle practices provide both a unique sense of personal identity to their adherents on the one hand, and a distinct and recognisable collective identity on the other (Cohen 2011).

Theoretically, the term 'lifestyle' is associated with the shifts identified with postFordism and post-modernism/late modernity (Giddens 1991). Under conditions of urbanisation and the transition from mass to specialised production, Western class distinctions began to loosen (Bell and Hollows, 2006). Identities became less based on logics of production and instead were increasingly fashioned through aesthetic consumption practices (Shields, 1992). Thus consumption practices were designed together into lifestyles (Featherstone, 1987), in which self-concept came to both direct consumption choices and itself became more and more constructed out of those choices: lifestyle consumption practices became 'decisions not only about how to act but who to be' (Giddens, 1991, p.81).

Whilst the importance of lifestyle to a sense of identity may have a longer history (Bell and Hollows 2006), it is how we choose our lifestyle that has become important. Whether we take Baudrillard's ideas that consumption no longer has use-value and instead has sign-value with which we are encouraged to play to construct a sense of identity (Poster 1998) or Giddens' (1991) ideas of the 'project of the self', implied is that our choice of lifestyle affects our sense of self and that our sense of self affects our (mobility) consumption choices. As such, processes of globalisation and changing technologies and societies have led to a 'de-traditionalisation', accompanied by an emphasis being placed on change, choice and reflexivity in and through lifestyle choices.

In arguing that we have more freedom to influence our lifestyle choices, however, issues of social exclusion and class still have resonance. Freedom of choice is limited in that 'forces, mechanisms and institutional arrangements' limit our ability to choose (Warde and 
Martens 1998, p. 129) and hence restrict our access to lifestyle choices. As Bourdieu (1984) notes when discussing class - 'some' are evidently more equal than 'others' in the decisions and freedom to make choices. Additionally as Skeggs (2004, p. 49) argues, pursuing an individualised lifestyle 'exists for a privileged few' and yet there remain tacit assumptions (amongst theorists) that this is a perspective that can be applied to many others.

Similarly, privileged citizens often see mobility as part of the everyday. Mobility is both familiar - whether we ourselves move or not - and, to some extent, taken for granted. Mobility depends on access to economic conditions, power, technology and networks that facilitate movement across borders and cultures (Cresswell 2001, 2010a). For example, Gogia (2006) illustrates the political asymmetries of mobile practices for different people in different locations, using the examples of Canadian nationals travelling to Mexico and vice versa. Dissimilar 'levels' of access to being physically mobile (as well as socially and virtually) reflect inconsistent hierarchical structures and processes that are bound up with gender, ethnicity, 'race', nationality, age, class and (dis)ability (Tesfahuney 1998).

Whilst lifestyles can be seen as largely fashioned through the consumption of sets of goods and services as a source of meaning or identity in everyday life (Chaney 1996, Shields 1992), and, by some, are taken 'more seriously than their careers' (Binkley 2004, p. 72), we observe that on-going voluntary physical mobility plays a crucial role in the performance of particular lifestyle choices. Thus, corporeal mobility is the quotidian for some persons; it is their everyday, and as such the choice of a mobile lifestyle extends to a way of life, which provides both a source of meaning and sense of personal identity to its adherents.

Therefore, a particular 'assemblage of goods, clothes, practices, experiences, appearance and bodily dispositions' are designed together into a lifestyle (Featherstone 1987, p. 59), uniquely distinguished by elements of corporeal mobility. Consequently, the de- 
traditionalisation associated with globalisation, in which both corporeal mobility has become more commonplace (Urry 2002) and lifestyles have become pivotal in the constitution of self-identity (Giddens 1991), has meant that lifestyle choices and forms of mobility increasingly co-mingle in ways that can be crucial to the lives of those who are privileged enough to access them. For said individuals, lifestyle mobilities are meaningfully performed as embodied everyday practice, including the inherent ambiguities, complexities and meanings of these movements and moorings. Thus, despite reflecting elements of travel, leisure, migration, tourism and work, this corporeal mobility, as we shall now demonstrate, is not captured by any one of these often bounded terms.

\section{Blurring travel, leisure and migration}

Although Hannam (2008) suggests that tourism has only recently begun to use some of geography's theoretical mainstays, Coles, Duval and Hall (2004) argue that tourism geography's utilisation of temporary mobility has provided an important point of intersection

- between tourism and geography - that has allowed a broader approach to understanding the meaning behind a range of corporeal mobilities. Specifically, Hall (2005) uses time, space and distance to demonstrate how the movement of tourists throughout their life courses can blur the boundaries with other forms of temporary mobility, including migration, travel for work, return migration and diasporas. This broader conceptualisation of tourism challenges existing views that tourism only occupies a 'liminal position' within geography (Gibson 2008, p. 418). For instance, Cohen's (2011) lifestyle travellers exemplify how tourism can 'tip' into an on-going lifestyle, wherein extended episodes of touristic experience, or temporary mobility, blur into conceptions of geographic migration. We argue that this fine 
line between tourism and migration can be better grasped through a lens of lifestyle mobilities.

Thus, while Hall's (2005) argument on tourism mobilities opened a wider door for considering the interrelations between these forms of physical mobility, the 'temporary', or episodic, aspect that has been taken forward from this perspective and imposed on much tourism mobilities research has limited the scope for understanding how mobilities can continue to play out over time. Bell and Ward (2000) endeavour a comparison of temporary mobility with permanent migration, defining temporary mobility as a non-permanent move of varying duration (which assumes a circular return to a usual residence) and permanent migration as a permanent change of usual residence. Beyond questions of usual residence and return, Bell and Ward (2000) further distinguish between temporary mobility and permanent migration through key dimensions of duration, frequency and seasonality.

Here we expand their comparison: alongside the questions of usual residence and return we add the concept of belonging, and further add a fourth dimension of temporality. Table 1 illustrates how when compared to temporary mobility and permanent migration, our conceptualisation of lifestyle mobility, defined here as on-going semi-permanent moves of varying duration, offers a lens into more complex forms of corporeal mobility that may involve multiple 'homes', 'belongings' and sustained mobility throughout the life course.

Lifestyle mobility differs from temporary mobility in that it is sustained as an ongoing fluid process, carrying on as everyday practice over time. However, it is important to remember that temporary mobility is also increasingly imbricated, at least in short bursts, in everyday life (Edensor 2007, Gale 2009). Lifestyle mobility also generally differs from temporary mobility by the higher significance placed on physical mobility itself as a defining aspect of one's identity, as we shall discuss further below. This identification with mobility is 
in contrast to both temporary mobility and permanent migration, wherein the performance of identity has closer links to place, whether that is with one's old or new residence.

Table 1: Comparison of Lifestyle Mobility to Temporary Mobility and Permanent Migration

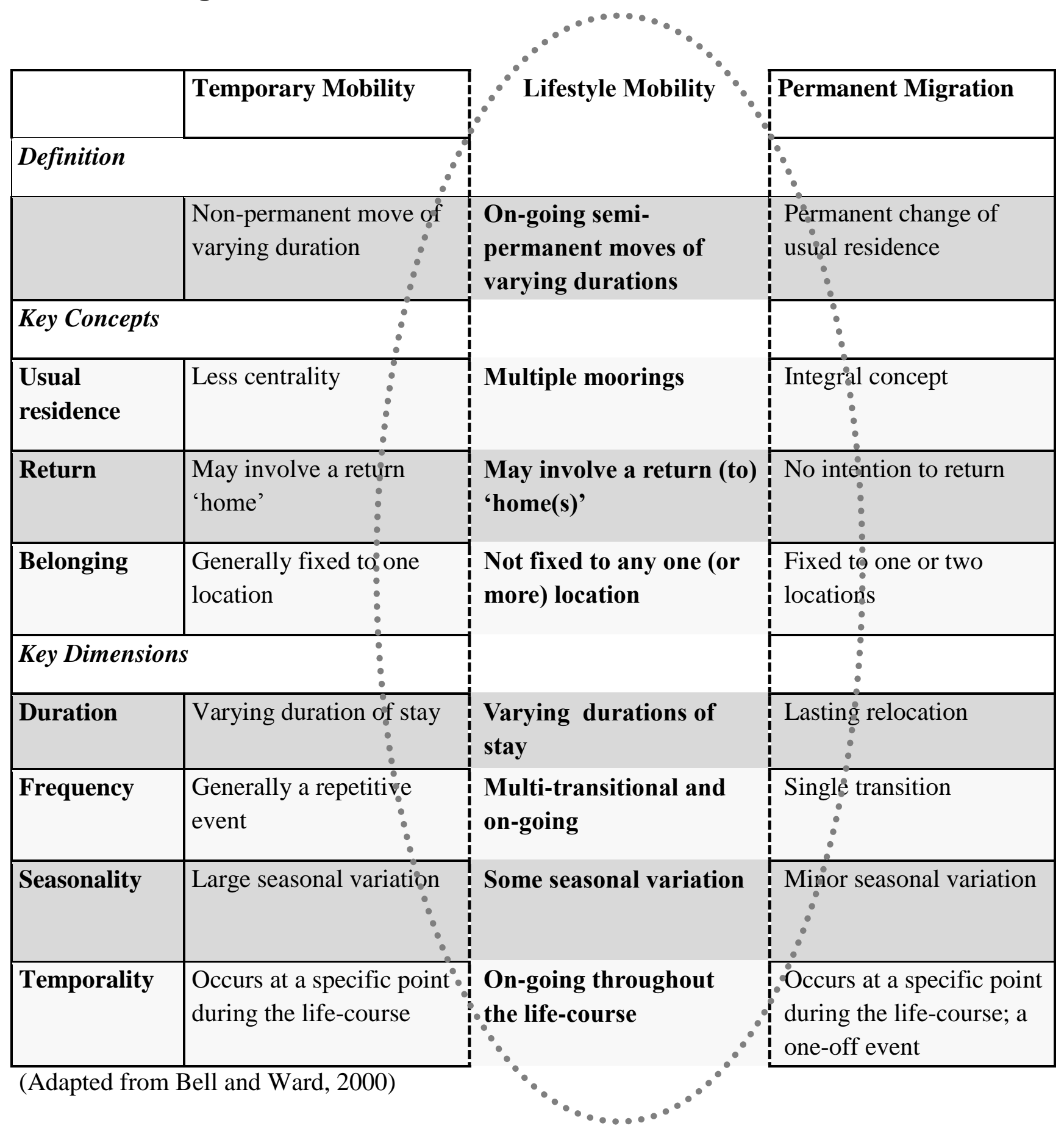


Unlike permanent migration, lifestyle mobility does not pre-suppose that there is no intention to return. Whilst a return to point of origin, or to any other point in the on-going movement process, may be part of lifestyle mobility, we argue that a return to any identified 'origin' cannot be presumed. Even though similarities might be found with temporary mobility, lifestyle mobility also differs in that the process is not dependent on returning to ' $\mathrm{a}$ ' home. Instead, lifestyle mobility pre-supposes the intention to move on, rather than move back. Through lifestyle mobility there is no 'one' place to which to return, and through time, there may be multiple 'homes' that one can return to and/or re-visit. This also illustrates the differences between lifestyle mobility and seasonal migration. Whilst seasonal migration can be lifestyle-led (see Thorpe 2012 on 'seasonal lifestyle sport migrants'), it has more fixed timeframes, is typically rotational and thus there is often an intention to move back (or on) once the specific period (i.e. the 'season') has finished. In contrast, lifestyle mobility is not dependent on time or seasons; though the borders between each of these concepts may become blurred at points. Although someone who has permanently chosen to relocate (e.g. lifestyle migrants, second home owners) may also have multiple moorings and diasporic associations, we suggest the destabilisation of home and away is particularly pronounced in lifestyle mobilities due to the consistent intention to move on. Lifestyle mobility consequently amplifies Hall's (2008) contention that tourism geography challenges ideas of permanence within migration studies (see also Duncan 2011).

O'Reilly (2003) argues that migration and tourism, which are often considered separately, need to be brought together within research so that an understanding can be developed as to how these two types of movement are interrelated. Furthermore, Williams and Hall (2000) highlight that the differences between tourism and migration have been weakly conceptualised, with the exception of second home development (e.g. Haldrup 2004, 
Hall and Müller 2004). There has been considerable neglect of 'the grey zone of the complex forms of mobility which lie on a continuum between permanent migration and tourism' (Williams and Hall 2000, p. 20), with labour, return, entrepreneurial, and retirement migration each identified as tourism-related.

In the last decade, however, there has been a growing body of scholarship that teases out the conceptual relationships between migration and tourism, with a particular focus on grasping the social-orientated aspects that may underlie migration. Benson and O'Reilly's (2009a) work on lifestyle migration, although differing from lifestyle mobility in that it tends to reflects forms of permanent and seasonal lifestyle-led relocation, is one example of approaching the relationships between migration and tourism through a social lens. Lifestyle migration (ibid, p. 1) examines how migration may be motivated by seeking 'a route to a better and more fulfilling way of life, especially in contrast to the one left behind'. In many cases, it is preceded by one or many tourism-related visits, thus again illustrating how tourism might 'tip' into migration. This approach to understanding some forms of migration as based on lifestyles is premised on the notion that 'lifestyle migrants are relatively affluent individuals of all ages, moving either part time or full time to places that, for various reasons, signify, for the migrant, a better quality of life' (Benson and O'Reilly 2009b, p. 609). Of course, to privilege any chosen way of life as 'better', whether that be in lifestyle migration, or within forms of lifestyle mobility, is to potentially offer a romantic reading of it. Linkages between romanticism and mobility have a long and critiqued history in nomadology (Cresswell 2006, Hannam 2009), embodied in the subject position of the nomad or "neonomad" (e.g. D’Andrea 2006).

Lifestyle mobility differs from lifestyle migration in that the latter is typically associated with a one-off lifestyle-led transition, such as choosing to move from northern 
Europe to rural France (e.g. Benson 2010), Spain (e.g. Casado-Díaz 2006, O’Reilly, 2003) or Portugal (e.g. Torkington 2012), from North to Latin America such as Panama (e.g. Spalding 2011) or Mexico (e.g. Morales 2010) or within the same country (e.g. Hoey 2005, 2006, Thulemark 2011). However, these moves are often then entangled with return visits to the old or natal 'home', particularly when links are strong and distances are manageable. Lifestyle migration can also involve more seasonal moves where lifestyle migrants are moving back and forth between two countries depending on, for example, climate conditions, which is sometimes the case for retirees (Gustafsson 2001). In contrast to lifestyle migration, lifestyle mobility is generally more fluid, on-going and multi-transitional, reflecting a 'rhizomatic' multiplicity (Deleuze and Guattari 1988), in which movement through space is both roots and routes (see Hannam 2009). However this is not exclusively the case, as for example even in long bouts of independent travel, on-going mobility is often disrupted through a need to return to the natal 'home', whether for social reasons or work (Cohen 2011), and it is to how work blends into lifestyle mobilities that we now turn.

\section{Collapsing work/leisure divides}

Work can both feature in and fold into forms of lifestyle mobility. Bianchi (2000) observes that the interfaces between migration, tourism, work and leisure are fluid, flexible and ambiguous in post-industrial mobility patterns. Accordingly, there have been attempts in the literature to chart variations in work and tourism depending on the primacy given to production or consumption (see Baranowski and Furlough 2001, Uriely 2001). More recently, Veijola (2009, p. 83-84; see also Zampoukos and Ioannides 2011) argues that when discussing work and tourism, it has often been studied from the 'comfort zone' of 
disciplinary home bases whereas it should instead be perceived 'as a paradigmatic sphere of the world in which people travel... and in which various forms of mobilities and immobilities structure both working life and individual life cycles, jobs and careers'.

For instance, Bianchi (2000) contends in his study with migrant tourist workers that they are neither strictly tourists nor workers. Similarly, Adler and Adler (1999) find resort workers are driven by dual motivations of leisure and work, an approach that counters a logic of production and is lifestyle-led through its fusion of production with consumption, or "prosumption". This alliance of leisure and work is further illustrated in Boon's (2006) study of ski resort workers, who support a skiing lifestyle through hotel work in the ski destination and in Duncan's (2008) research on young budget travellers whose working and travelling experiences are indicative of the blurring boundaries between leisure and work.

Additional research by Wilson, Fisher and Moore (2009), in their study of working holidaymakers, who are backpackers, on a 'gap year' or an 'overseas experience', highlights ways in which conventional accounts of travel, work and migration fuse. Therefore, the contemporary backpacker - or independent traveller - is often simultaneously 'an employee, a student, a visitor, a seasonal worker, holidaymaker, a semi-permanent resident, and potentially many other roles and identities' (Allon, Anderson and Bushell 2008, p. 75). The divide between work and not-work, or work and leisure, can therefore be persistently and continually blurred. As Fincham (2008, p. 619) states, the distinctions between work and not being at work are often overstated and for him (through his research with bike messengers), this distinction can become 'relatively meaningless'.

Other work elements can impact on lifestyle mobilities. For instance, research into academic mobility has identified a number of distinct patterns inherent in these mobilities and highlights differences in these academics' mobility practices globally, but also temporally 
and spatially (Hoffman 2009). Yet, perhaps more importantly is the plethora of studies on other types of 'work' where lifestyle and mobility elements are obvious yet have played little part in the research. For instance, research on highly skilled migrants (see for instance Koser and Salt 1997, Beaverstock 2002, 2005, Ho 2011) addresses issues of transnationalism, global-local networks, citizenship and belonging, often examining participants' perspectives from both economic and socio-cultural angles; however the theoretical lens of migration rather than mobility is most often applied. Whilst these examples lead back to arguments outlined earlier by Bourdieu (1984) and Skeggs (2004) about who is able to combine lifestyle with - in these instances - career and mobility, there are also examples of how career, lifestyle and travel intersect at other levels. As an example, Walsh's (2006) paper on an expatriate hairdresser in Dubai illustrates the everyday experiences and tensions implicated in lifestyle mobilities. Walsh (2006, p. 269) outlines 'Jane', and encapsulates her respondent's previous experiences by saying:

[S]he had been living in Dubai for 6 months. She expected to stay for a couple of years, but she did not have fixed plans to settle for long, move back to Britain or move on elsewhere. Originally from Chester, England, Jane had also lived in Spain and Australia, and travelled widely as a 'backpacker' in Asia.

Whilst Walsh's (2006) paper aims to highlight experiences hitherto largely ignored in migration research by challenging geographies of belonging, specifically through place attachment and detachment, the above quote illustrates how, in many ways, Jane's experiences are also about lifestyle mobility: she has had on-going movements of varying durations, has multiple moorings and has no immediate plans to return 'home'. It is important to note, however, that whilst lifestyle mobility can include work and career, we see the dominant purpose of its associated movements as lifestyle-led rather than driven by economic 
gain or a logic of production. As such, a career is not a defining feature of lifestyle mobility, as Pearce and Lee (2007) might have intended when referring to 'travel career patterns'.

As we have illustrated, lifestyle mobilities are thus characterised by an increased blurring between work and leisure. Likewise, a binary divide between 'home' and 'away' is challenged by lifestyle mobilities, and it is to tensions within this dichotomy that we now turn.

\section{Destabilising binaries of 'home' and 'away'}

Underpinning mobility are transnationalism and globalisation, which have consequences not only for everyday mobility, but also for place-making (Gale 2008, Tomlinson 1999). Lifestyle mobility, as with transnationalism and globalisation more broadly, is bound up with issues of belonging in, to and with place, as people may relate to place in myriad ways, such as by a sense of home (in place), through a sense of citizenship (to place) and through affinity with place (Conradson and McKay 2007). Increased mobility can create multiple places of belonging and aspects of transnationalism. For instance, if a place is taken as a geographical space with a meaning to someone, 'home' can become a definition for that place. However, to see home as rooted in one place is perhaps outdated. Germann Molz (2008) discusses the concept of a 'global abode' in her study of round-the-world travel, in which the interactions of mobility, home and belonging are explored. Within the notion of a global adobe, the 'travelers' ability to be at home in mobility allows them to be at home in the world', a veritable 'home-on-the-move' (Germann Molz 2008, p. 338). William and McIntyre (2001, p. 400) also suggest that home is no longer 'just' one place and that: 
Modern ways of living give the old adage "home is where the heart is" new meaning. While it has always been suggested that the notion of home is inseparable from one's sense of self, it also implies that home is not necessarily where one physically (or legally) resides. The forces of modernization and globalization not only make this more true, they also tend to dislodge one's heart (identity) from singular roots and redistribute it across space like so many rhizomes.

Thus, for individuals whose mobilities have moored them in multiple places for extended periods of time, one place might not take primacy as 'home' over another (see for example Gustafson's (2001) study on transnational lifestyles among Swedish retirement migrants in Spain and their differences in single/multiple place attachment and cultural acceptance). The related concept of 'multiple dwelling' can be used as a device to study not only second homes, as has been its most common usage, but also 'how people are managing the increasing complexity of modern living' (McIntyre 2006, p. 14). Therefore, our identities and sense of belonging to 'home' do not, by any means, have to be fixed. The challenge, Ralph and Staeheli (2011, p. 518) argue, 'is to conceptualize the simultaneity of home as sedentarist and as mobile'. For some, even the act of mobility in itself might be the sense of stability that a home can give (Terranova-Webb 2010).

A case in point is Terranova-Webb's (2010) examination of the mobilities of circus performers. Her work, a mobile ethnography of a circus in the United States, provides a change in the 'story' of the circus from one of excitement and romance attributed to travelling performers, typically viewed from a sedentarist perspective, to one instead as viewed from the banal, daily, work and grind of the performer on the road. Terranova-Webb illustrates that mobility is more than documenting movement and is instead about 
understanding how it is/has become a complex process of lived relations (Adey 2010). As Cresswell (2010a) suggests, mobilities, as a way of being in the world, are practised, embodied, experienced and represented in a variety of ways. Thus for the circus in Terranova-Webb's study, the mobile lifestyle of the travelling performers is about continual reproduction of daily routine and the rhythm of mobility. Whilst consistent, it is also flexible, and so the circus maintains its particular form of mobility and lifestyle, yet also continually renews and restores itself through these same processes.

Thus, Terranova-Webb (2010) introduces the concept of 'stable mobility'. She refers to three intertwining situations at work in the circus:

The first is a situation of continuing movement. The second is an understanding that the production of movement continually creates a recognizable situation. The third is understanding that stable and recognizable do not mean fixity or continual fluidity, but instead flexibility (ibid, p. 3).

Her work therefore recognises that flexibility in processes of mobility is necessary for the continuing condition of movement. These disruptions are 'moments of refocusing and maintenance to the mobility processes of Circus which create a stable and recognizable place of Circus on the move' (ibid, p. 11). Terranova-Webb concludes that these often subtle disruptions allow the people of the circus to recreate (and maintain) a recognisable stable situation for themselves.

Therefore, the continual movement of the Circus becomes stable and an embedded attribute in the making, maintaining a constant renewal of a circus lifestyle. We thus go back to Germann Molz's (2008) notion of 'home-on-the-move', wherein an abode is constructed in and through lifestyle mobility. As stated earlier, we conceive lifestyle mobility as an ongoing fluid process, carrying on as everyday practice over time. Hence, Terranova-Webb's 
(2010) travelling performers perform their everyday whilst continually on the move. Yet, these performers also differ somewhat in that whereas lifestyle mobilities may involve returns to home(s), these performers take their homes with them. However, this allows the mundane, the everyday, to continue through their multiple moorings - returning to places visited the year before, on sites that are the same, however also different as time has moved on. Consequently, they are bound to the place of the circus by roots and routes (Hannam, 2009).

Connection to places can thus be examined at various scales. Whereas much of our discussion suggests that lifestyle mobility can be a global, transnational endeavour, it can also occur at other scales - Terranova-Webb's (2010) example illustrates the national for instance. Yet, more broadly, this does not suppose that those undertaking this type of mobile lifestyle are not entrenched in a richly transnational world. 'Translocal subjectivities' are relevant here in describing the 'multiply-located senses of self amongst those who inhabit transnational social fields' (Conradson and McKay 2007, p. 168; see also Appadurai 1996). Conradson and McKay (2007, p. 169) observe that these selves often relate at different scales - to 'localities within nations [rather] than to nation-states', and that these multiple emplacements often cause quandaries in maintaining commitments to friends, family and community.

This suggests that the tension between mobility, lifestyle and home (defined as a fixed place or space) remains contested. As Butcher (2010, p. 23) observes, 'mobility has changed the relationship between self and place including definitions of that most intimate of spaces, home, in all its manifestations: as a physical place and a metaphor for cultural belonging to a place of origin'. Thus, for many people, the material and imaginative geographies of home are fluid, complex and vague; 'home is shaped by memories as well as everyday life in the present' (Blunt and Dowling 2006, p. 202). 
But being mobile does not preclude a 'homing desire' (Brah 1996 cited in Blunt and Dowling 2006, p. 199). In her research on highly mobile individuals, Butcher (2010) argues there is still a 'need' for home, even if this home becomes multi-sited. She suggests that being a 'global citizen' does not negate the need to 'feel the ground beneath their feet' and as such to have somewhere (or many places) that can be called home (ibid, p. 34). Consequently, the multiple moorings that one may have with a mobile lifestyle do not imply that place has been deterritorialised and that national boundaries have fully receded: for instance in the "uncomfortable realizations of difference ... [there] could be the reinforcement of borders' (ibid, p. 33). Rather as Bricknell and Datta (2011, p. 9) suggest, it is necessary instead to consider a grounded transnationalism which recognises that transnational connections are 'only possible through local-local connections across national spaces'. These issues, often associated with labour migrants, refugees, diaspora and asylum seekers, are also highly relevant when people choose to move for lifestyle reasons. Returning to Germann Molz's (2008) 'global abode' then, where home is in the travellers' very mobility: this does not mean they do not have somewhere they consider a physical home, nor does it exclude them finding and making multiple homes on and through their travels.

Boundaries between home and away can also be blurred by the possibilities given by new technologies (Paris 2010, 2012). Those who choose to be mobile through their lifestyle can, through emerging technologies be 'at home' while being 'away' (Germann Molz 2012, White and White 2007; see also Mascheroni 2007). Places are then 'not so much bounded areas as open and porous networks of social relations' (Massey 1994, p. 121). White and White's (2004) discussion of the phenomenon of long-term travel by older adults, also termed 'grey nomads' (Onyx and Leonard 2005, Patterson, Pegg and Litster 2011) highlights these possibilities. Indeed, whilst it has been suggested that grey nomads are in transition and thus 
neither 'here' nor 'there' (White and White 2004), as they may be geographically distant from friends and family, they are in fact neither disengaged nor isolated (Patterson et al. 2011). Contemporary technology allows temporal and spatial aspects of long-term travel to disintegrate (see Mascheroni 2007, O’Regan 2008), and affords a multiplicity of connections - and so possible moorings - in and through these movements that are representative of lifestyle mobility.

\section{Complexities of identity, place and belonging}

The destabilisation of home and away characteristic of lifestyle mobilities engenders tangled senses of identity and belonging. Yet within the movement inherent to lifestyle mobilities, place remains significant. It has been argued that place is not only a geographical space but also for individuals, place constitutes a material form and an investment with meaning and value (Gieryn 2000). For instance, within the movements of grey nomads, White and White (2004) signal how lifestyle mobilities may engender a re-examination of identity, as the land we inhabit, and are mobile through, may mirror our (changing) selves.

Consequently, as an increasingly diverse range of people experience some form of transnationality, and at the same time, participate in transnational spaces (see Jackson, Crang and Dwyer 2004), there is a clear need to move towards understanding 'the meaning behind the range of mobilities undertaken by individuals', especially through notions of place attachment and identity (Hall 2005, 2008, p. 15). Sheller and Urry (2006) thus argue that the mobilities paradigm must be brought to bear on questions of the deterritorialisation of identities and belonging. Ghosh and Wang (2003, p. 278) suggest that transnationalism is 
essentially an individual process wherein one composes a sense of multiple or hybrid selves through 'an abstract awareness of one's self, diaspora and multiple belonging'.

Mobility choices can be subsumed into self-identities; for example in Nóvoa’s (2012, p. 367) mobile ethnography of musicians on tour, he argues that 'the mobility of a musician is also one of the most relevant features in his or her life, conferring meaning to his identity as such and configuring him as a figure of mobility'. As Cohen's $(2010,2011)$ research on lifestyle travellers - individuals who backpack as an on-going way of life - illustrates, performing identity is an important facet of lifestyle mobility. It is worth noting that this playing and working with identities through movement between and within place is not just the privilege of the young however, as is implied in much of the previous backpacker literature (e.g. O'Reilly 2006, Richards and King 2003). Place is hence pivotal in constructing transnational identities as individual attachment to a single place loosens, dividing attention and presence between two places or more (Hannerz 2002; see also Gustafson 2001).

Rather than being connected to one place, therefore, we often now have multiple links to multiple places (and perhaps even multiple nationalities). In this sense, the importance of national boundaries may recede and familial and friendship networks (both corporeal and virtual) take prominence (Conradson and Latham 2005, see also Ho 2008). Studies of transnational peoples have shown these individuals to construct intricate, multi-webbed networks of on-going social relations that span countries of origin through multiple countries of visitation or settlement (Mitchell 2009). This process is now further facilitated and sustained through the interactions provided by new mobile social media and locative social networks (for examples see Mascheroni 2007, O’Regan 2008). 
A note of caution needs mention however as to the tensions that may lie in forging multiple senses of belonging. Desforges (2000) outlined how some of the young women he interviewed in his study of travel and identity felt that they had to hide aspects of their new sense of self upon their return home from travelling, as it did not 'fit' with prior expectations held of/about them. As Cohen (2010) suggests, whereas some adherents to highly mobile lifestyles may perceive their personal identities as partially constructed through the appropriation of their experiences and exposure to a variety of cultural forms, a process reflecting Hannerz's (2002) description of 'aesthetic cosmopolitanism', one darker side of mobility is that sustained corporeal movement through a diversity of cultural praxes can also contribute to a sense of identity confusion, or of feeling metaphorically 'lost'. A lens of lifestyle mobilities hence contributes to these quintessential questions of how we understand ourselves and relate to place in late modernity, by unpacking how identity constitution and notions of belonging and place attachment are affected by, and affect, highly mobile lifestyles. Such analyses are of growing importance as mobility increasingly becomes a key feature of various ways of life (Urry 2002).

\section{Conclusion}

In this paper, we have begun to redress the limitations of current knowledge between mobilities, travel, leisure and migration through offering the lens of lifestyle mobilities. Like Noy and Cohen (2005), who highlight that 'lifelong wanderers' have rarely been the subject of empirical research, and D'Andrea (2006), who discusses the increasing importance of 'neo-nomadism' under conditions of accelerating globalisation, so we argue that the study of the intersections of mobility and lifestyle, two areas in their own right of increasing importance in the social sciences, have not been subject to a sufficient sustained examination. 
In developing the concept of lifestyle mobilities, we have illustrated how it can offer a wider perspective through which to view those whose mobile lifestyles cannot be easily 'pigeonholed'. At the same time, as we have suggested in Table 1, in comparison with temporary mobility and permanent migration, lifestyle mobility allows for a wider grasp of the interconnections of contemporary travel, leisure and migration.

We have furthermore demonstrated how practices of lifestyle mobility contribute to and are exemplary of a breakdown in a binary divide between work and leisure, as the two often fold into each other and become blurred in lifestyle-led mobility patterns. Likewise, our argument showed how lifestyle mobilities are characterised by destabilised notions of 'home' and 'away', as on-going moves of various durations contribute to multiple moorings. While we recognised this feature as also potentially common to lifestyle migrants, second home owners or those with diasporic associations, in lifestyle mobilities this destabilisation of home and away is particularly pronounced. A lens of lifestyle mobility therefore challenges ideas of permanence in migration studies, as lifestyle mobility pre-supposes the intention to move on, rather than move back. Finally, we unpacked issues of identity construction, belonging and place attachment associated with sustained corporeal mobility and highlighted how these issues may further resonate in society as mobile lifestyles become more commonplace.

Our analysis has important implications for mobilities studies and research on how mobility choices are used to manage the complexity associated with modern living. A focus on lifestyle mobility brings to the fore the subsumption of identity through mobility and continuing processes of de-differentiation in social life: on-going corporeal mobility weakens conventional binaries such as work/leisure and home/away, and challenges discrete notions of travel, leisure and migration. As our effort here has been to conceptualise a lens of lifestyle 
mobilities, including its basic properties, significance and implications, we have necessarily relied on related social phenomena (i.e. lifestyle travellers, grey nomads and circus performers) to illustrate our argument. We hope to have provided mobilities researchers a basis for the empirical study of other patterns of mobile social life where a lifestyle mobilities perspective may be particularly useful. Although lifestyle mobilities is an emergent perspective, it is already being applied to patterns of mobility such as those of peripatetic artists (Bell in press), hitchhikers (O'Regan in press), and transient rock climbers (RicklyBoyd in press).

Yet, even as we suggest the need to examine lifestyle mobilities further, so we need to ask new questions that recognise that lifestyles of mobility are situated in changing economic, environmental and techno-social contexts. Questions hence emerge as to if and how the fluidity of forms of lifestyle mobility may be disrupted, or become even more entrenched, by economic crises in some Western countries, and concurrently, how emergent forms of lifestyle mobility may be created in the rise in power of other nations and populaces. Additionally, much of what we now see as mobility relies on carbon-dependent fuel. How will these forms of lifestyle mobility change and react as the world begins to deal with shortages in these types of fuel? How will our carbon-dependent (and often privileged) mobilities be impacted by future alternative transport systems that mean less mobility - or slower mobility? Will types of sustainable lifestyle mobility surface to allow these global, transnational peoples to continue their ways of life and so their lifestyles?

With patterns of lifestyle mobility often only available to the relatively privileged, the power asymmetries within lifestyle mobility warrant further inquiry. Future research may thus adopt a social class perspective and take the question farther of 'who' is able to choose lifestyle mobilities. Linked to this issue, is the question of how the characteristics of lifestyle 
mobility will change as available technologies continue to advance. Already Mascheroni's (2007) work has suggested that communities are now mobile and existing on- and off-line with the significance of time and space being, necessarily, reconfigured. Will these transformations make lifestyle mobility more accessible to wider populations and contribute further to the reconfiguring of place attachment?

In asking these questions and in aiming to problematise the intersections of travel, leisure and migration through the lens of lifestyle mobilities, so we hope to have opened a fresh interdisciplinary route with which to further interrogate the grey zone between temporary mobility and permanent migration, where a range of social phenomena are challenging and circumventing conventional understandings of travel and migration, destabilising binaries of work/leisure and home/away and contributing to shifts in how belonging and identity are understood.

\section{References}

Adey, P., 2010. Mobility. London: Routledge.

Adler, P.A. and Adler, P., 1999. Transience and the Postmodern Self: The Geographic Mobility of Resort Workers. The Sociological Quarterly, 40(1), 31-58.

Allon, F., Anderson, K. and Bushell, R., 2008. Mutant Mobilities: Backpacker Tourism in 'Global' Sydney. Mobilities, 3(1), 73-94.

Appadurai, A., 1996. Modernity at Large: Cultural Dimensions of Globalization. Minneapolis: University of Minnesota Press.

Baranowski, S. and Furlough, E., 2001. Introduction. In: S. Baranowski and E. Furlough, eds, Being Elsewhere: Tourism, Consumer Culture, and Identity in Modern Europe and North America. Ann Arbor: University of Michigan Press, 1-31.

Bauman, Z., 2000. Liquid Modernity. Cambridge: Polity.

Beaverstock, J., 2002. Transnational elites in global cities: British expatriates in Singapore's financial district. Geoforum, 33(4), 525-538. 
Beaverstock, J., 2005. Transnational elites in the city: British highly-skilled inter-company transferees in New York City's Financial District. Journal of Ethnic and Migration Studies, 31(2), 245-268.

Bell, C., 2014. Peripatetic Artists: Creative Mobility and Resourceful Displacement. In: T. Duncan, S.A. Cohen and M. Thulemark, eds, Lifestyle Mobilities: Intersections of Travel, Leisure and Migration. Farnham: Ashgate.

Bell, D. and Hollows, J., 2006. Towards a History of Lifestyle. In: D. Bell, ed. Historicizing Lifestyle: Mediating Taste, Consumption and Identity from the 1900s to 1970s. Brookfield: Ashgate, 1-19.

Bell, M. and Ward, G., 2000. Comparing Temporary Mobility with Permanent Migration. Tourism Geographies, 2(1), 87-107.

Benson, M., 2010 The context and trajectory of lifestyle migration- the case of the British residents in Southwest France. European Societies, 12(1), 45-64.

Benson, M., 2011 The Movement Beyond (Lifestyle) Migration: Mobile Practices and the Constitution of a Better Way of Life. Mobilities, 6(2), 221-235.

Benson, M. and O'Reilly, K., eds., 2009a. Lifestyle Migration - Expectations, Aspirations and Experiences. Farnham: Ashgate.

Benson, M. and O'Reilly, K., 2009b. Migration and the Search for a Better Way of Life: A Critical Exploration of Lifestyle Migration. The Sociological Review, 57(3), 608-625.

Bianchi, R.V., 2000. Migrant Tourist-workers: Exploring the 'Contact Zones' of Postindustrial Tourism. Current Issues in Tourism, 3(2), 107-137.

Binkley, S., 2004 Everybody's Life is Like a Spiral: Narrating Post-Fordism in the Lifestyle Movement of the 1970s. Cultural Studies <- -> Critical Methodologies, 4(1), 71-96.

Blunt, A. and Dowling, R., 2006. Home. London: Routledge.

Boon, B., 2006. When Leisure and Work are Allies: The Case of Skiers and Tourist Resort Hotels. Career Development International, 11(7), 594-608.

Bourdieu, P., 1984. Distinction: A Social Critique of the Judgement of Taste. Cambridge, MA: Harvard University Press.

Bricknell, K. and Datta, A. 2011. Introduction: Translocal Geographies. In: K. Bricknell and A. data (eds.). Translocal Geographies: Spaces, Places and Connections. Farnham, Ashgate, 3-20.

Butcher, M., 2010. From 'Fish Out of Water' to 'Fitting In': The Challenge of Re-placing Home in a Mobile World. Population, Space and Place, 16(1), 23-36. 
Casado-Díaz, M., 2006. 'Retiring to Spain: An Analysis of Difference among North European Nationals'. Journal of Ethnic and Migration Studies, 32(8), 1321-1339.

Chaney, D., 1996. Lifestyles. London: Routledge.

Cohen, E. and Cohen, S.A., 2012. Current Sociological Theories and Issues in Tourism. Annals of Tourism Research, 39(4). DOI: 10.1016/j.annals.2012.07.009.

Cohen, S.A., 2010. Personal Identity (De)formation Among Lifestyle Travellers: A Doubleedged Sword. Leisure Studies, 29(3), 289-301.

Cohen, S.A., 2011 Lifestyle Travellers: Backpacking as a Way of Life. Annals of Tourism Research, 38(4), 1535-1555.

Coles, T., Duval, D. and Hall, C.M., 2004 Tourism, Mobility and Global Communities: New Approaches to Theorising Tourism and Tourist Spaces. In: W. Theobold, ed. Global Tourism: The Next Decade. 3rd ed. Oxford: Butterworth Heinemann, 463-481.

Conradson, D. and Latham, A., 2005. Friendship, Networks and Transnationality in a World City: Antipodean Transmigrants in London. Journal of Ethnic and Migration Studies, 31(2), 287-305.

Conradson, D. and McKay, D., 2007. Translocal Subjectivities: Mobility, Connection, Emotion. Mobilities, 2(2), 167-174.

Cresswell, T., 2001. The Production of Mobilities. New Formations 43(1), 11-25.

Cresswell, T., 2006. On the Move: Mobility in the Modern Western World. London: Routledge.

Cresswell, T., 2010a. Towards a Politics of Mobility. Environment and Planning D; Society and Space, 28(1), 17-31.

Cresswell, T., 2010b. Mobilities I: Catching up. Progress in Human Geography, 35(4), 550558.

D'Andrea, A., 2006. Neo-nomadism: A Theory of Post-identitarian Mobility in the Global Age. Mobilities, 1(1), 95-119.

Deleuze, G. and Guattari, F., 1988. A Thousand Plateaus. London: The Athlone Press.

Desforges, L., 2000. Traveling the World: Identity and Travel Biography. Annals of Tourism Research, 27(4), 926-945.

Duncan, T., 2008, The Internationalisation of Tourism Labour Markets: Working and Playing in a Ski Resort. In: C.M. Hall and T. Coles, eds. International Business and Tourism. London: Routledge, 181-194. 
Duncan, T., 2011. The mobilities turn and the geography of tourism. In: J. Wilson, ed. The Routledge Handbook of Tourism Geographies. London: Routledge, 113-120.

Edensor, T., 2007. Mundane Mobilities, Performances and Spaces of Tourism. Social and Cultural Geography, 8(2), 199-215.

Featherstone, M., 1987. Lifestyle and Consumer Culture. Theory, Culture and Society, 4(1), $55-70$.

Fincham, B., 2008. Balance is everything: Bicycle Messengers, Work and Leisure, Sociology, 42(4), 618-634.

Gale, T., 2008. The End of Tourism, or Endings in Tourism?. In: P.M. Burns and M. Novelli, eds. Tourism and Mobilities. Wallingford: CABI Publishing, 1-14.

Gale, T., 2009. Urban beaches, virtual worlds and 'the end of tourism'. Mobilities, 4(1), 119138.

Germann Molz, J., 2008. Global Abode: Home and Mobility in Narratives of Round-theWorld Travel. Space and Culture, 11(4), 325-342.

Germann Molz, J., 2012. Travel Connections: Tourism, Technology and Togetherness in a Mobile World. London: Routledge.

Ghosh, S. and Wang, L., 2003. Transnationalism and Identity: A Tale of Two Faces and Multiple Lives. The Canadian Geographer, 47(3), 269-282.

Gibson, C., 2008, Locating Geographies of Tourism. Progress in Human Geography, 32(3), 407-422.

Giddens, A., 1991. Modernity and Self-identity: Self and Society in the Late Modern Age. Cambridge: Polity Press.

Gieryn, T.F., 2000. A space for place in sociology. Annual Review of Sociology, 26, 463-495.

Gogia, N., 2006. Unpacking Corporeal Mobilities: The Global Voyages of Labour and Leisure. Environment and Planning A, 38(2), 359-375.

Gustafson, P., 2001. Retirement migration and transnational lifestyles. Aging and Society, 21, 371-394.

Haldrup, M., 2004. Laid-back Mobilities: Second-Home Holidays in Time and Space. Tourism Geographies, 6(4), 434-454.

Hall, C.M., 2005. Reconsidering the Geography of Tourism and Contemporary Mobility. Geographical Research, 43(2), 125-139. 
Hall, C.M., 2008. Of Time and Space and Other Things: Laws of Tourism and the Geographies of Contemporary Mobilities. In: P.M. Burns and M. Novelli, eds. Tourism and Mobilities. Wallingford: CABI Publishing, 15-32.

Hall, C.M. and Müller, D.K., 2004. Tourism, Mobility and Second Homes: Between Elite Landscapes and Common Ground. Toronto: Channel View.

Hannam, K., 2008. Tourism Geographies, Tourist Studies and the Turn Towards Mobilities. Geography Compass, 2(1), 127-139.

Hannam, K., 2009. The End of Tourism? Nomadology and the Mobilities Paradigm. In: J. Tribe, ed. Philosophical Issues in Tourism. Bristol: Channel View, 101-113.

Hannam, K., Sheller, M. and Urry, J., 2006. Editorial: Mobilities, Immobilities and Moorings. Mobilities, 1(1), 1-22.

Hannerz, U., 2002. Where We Are and Who We Want to Be. In: U. Hedetoft and M. Hjort, eds, The Postnational Self: Belonging and Identity. Minneapolis: University of Minnesota Press, 217-232.

Ho, E., 2008. "Flexible Citizenship" or familial Ties that Bind? Singaporean Transmigrants in London. International Migration, 46(4), 145-175.

Ho, E., 2011. Migration trajectories of 'highly skilled' middling transnationals: Singaporean transmigrants in London. Population, Space and Place, 17(1), 116-129.

Hoey, A. B., 2005. From Pi to Pie: Moral Narratives of Noneconomic Migration and Starting Over in the Postindustrial Midwest. Journal of Contemporary Ethnography, 34(5), 586-624

Hoey, A. B., 2006. Gray Suit or Brown Carhartt: Narrative Transition, Relocation, and Reorientation in the Lives of Corporate Refugees, Journal of Anthropological Research, 62(3), 347-371

Hoffman, D., 2009. Changing Academic Mobility Patterns and International Migration: What will Academic Mobility Mean in the $21^{\text {st }}$ Century? Journal of Studies in International Education, 13(3), 347-364.

Jackson, P., Crang, P. and Dwyer, C., 2004. Introduction. In: P. Jackson, P. Crang and C. Dwyer, eds. Transnational Spaces. London: Routledge, 1-23.

Koser, K. and Salt, J., 1997. The Geography of Highly Skilled International Migration. International Journal of Population Geography, 3, 285-303.

Mascheroni, G., 2007. Global Nomads' Network and Mobile Sociality: Exploring new media uses on the move. Information, Communication and Society, 10(4), 527-546.

Massey, D., 1994. Space, Place and Gender. Minneapolis: University of Minnesota Press. 
McIntyre, N., 2006. Introduction. In: McIntyre, N. Williams, D. and McHuge, K., eds. Multiple Dwelling and Tourism Negotiating Place, Home and Identity. Oxfordshire: CABI Publishing, 3-14.

McIntyre, N., 2009. Re-thinking amenity migration: Integrating mobility, lifestyle and socialecological systems Die Erde, 140(3), 229-250.

Mitchell, K., 2009. Transnationalism In: R.J. Johnston, D. Gregory, G. Pratt, M.J. Watts and S. Whatmore, eds. The Dictionary of Human Geography. 5th ed. Oxford: Wiley-Blackwell, 772-773.

Morales, L.O., 2010. The US citizens Retirement Migration to Los Cabos, Mexico. Profile and social effects. Recreation and Society in Africa, Asia and Latin America, 1(1), 75-92.

Nóvoa, A., 2012. Musicians on the Move: Mobilities and Identities of a Band on the Road. Mobilities, 7(3), 349-368.

Noy, C., and Cohen, E., 2005. Introduction: Backpacking as a Rite of Passage in Israel. In: C. Noy and E. Cohen, eds. Israel Backpackers and Their Society: A View From Afar. Albany: State University of New York, 1-13.

Onyx, J. and Leonard, R., 2005. Australian Grey Nomands and American Snowbirds: Similarities and differences. The Journal of Tourism Studies, 16(1), 61-68.

O'Regan, M., 2008. Hypermobility in Backpacker Lifestyles: The Emeregence of the Backpacker Café. In: P. M. Burns and M. Novelli, eds. Tourism and Mobilities: Local Global Connections. Wallingford: CABI Publishing, 109-132.

O'Regan, M., 2014. Others Have the Clock But We Have Time: Alternative Lifestyle Mobilities and the Resurgence of Hitchhiking. In: T. Duncan, S.A. Cohen and M. Thulemark, eds, Lifestyle Mobilities: Intersections of Travel, Leisure and Migration. Farnham: Ashgate.

O'Reilly, C. C., 2006. From drifter to gap year tourist: Mainstreaming backpacker travel. Annals of Tourism Research, 33(4), 998-1017.

O'Reilly, K., 2003. When is a Tourist? The Articulation of Tourism and Migration in Spain's Costa del Sol. Tourist Studies, 3(3), 301-317.

Paris, C., 2010. The Virtualization of Backpacker Culture: Virtual Mooring, Sustained Interactions and Enhanced Mobilities. In: K. Hannam and A. Diekmann, eds. Beyond Backpacker Tourism: Mobilities and Experiences. Bristol: Channel View Publications, 4063.

Paris, C., 2012. Flashpackers: An emerging sub-culture? Annals of Tourism Research, 39(2), 1094-115.

Patterson, I., Pegg, S. and Litster, J., 2011. Grey Nomads on Tour: A Revolution in Travel and Tourism for Older Adults. Tourism Analysis, 16(3), 283-294. 
Pearce, P. L., and Lee, U., 2007. Developing the Travel Career Approach to Tourist Motivation. Journal of Travel Research, 43(3), 226-237.

Poster, M., 1998. Virtual Ethnicity: Tribal Identity in an Age of Global Communications. In: S. Jones, ed. Cyberspace 2.0: Revisiting Computer-mediated Communication and Community. London: Sage Publications, 184-211.

Ralph, D. and Staeheli, L., 2011. Home and Migration: Mobilities, Belongings and Identities. Geography Compass, 5(7), 517-530.

Richards, G. and King, B., 2003. Youth travel and backpacking. Travel and Tourism Analyst, $6,1-23$.

Rickly-Boyd, J.M., 2014. 'Dirtbags': Mobility, Community and Rock Climbing as Performative of Identity. In: T. Duncan, S.A. Cohen and M. Thulemark, eds, Lifestyle Mobilities: Intersections of Travel, Leisure and Migration. Farnham: Ashgate.

Sheller, M. and Urry, J., 2006. The New Mobilities Paradigm. Environment and Planning A, $38(2), 207-226$

Shields, R., 1992. Spaces for the Subject of Consumption. In: R. Shields, ed. Lifestyle Shopping: The Subject of Consumption. London: Routledge, 1-20.

Skeggs, B., 2004. Class, Self, Culture. London: Routledge.

Sobel, M., 1981. Lifestyle and Social Structure: Concepts, Definitions and Analyses. New York: Academic Press.

Spalding, A.K. 2011. Remaking lives abroad: Lifestyle migration and socio-environmental change in Bocas Del Toro, Panama. Thesis (PhD). University of California, Santa Cruz.

Stebbins, R. A., 1997. Lifestyle as a Generic Concept in Ethnographic Research. Quality and Quantity, 31(4), 347-360.

Terranova-Webb, A., 2010. Getting Down the Road: Understanding Stable Mobility in an American Circus. PhD Thesis, Department of Geography, Open University.

Tesfahuney, M., 1998. Mobility, Racism and Geopolitics. Political Geography, 17(5), 499515.

Thorpe, H., 2012. Transnational Mobilities in Snowboarding Culture: Travel, Tourism and Lifestyle Migration. Mobilities, 7(2), 317-345.

Thulemark, M., 2011. A New Life in the Mountains: Changing Lifestyles among In-Migrants in Wanaka, New Zealand. Recreation and Society in Africa, Asia and Latin America, 2(1), $35-50$.

Tomlinson, J., 1999. Globalization: The Human Consequences. London: Routledge. 
Torkington, K., 2012. Place and Lifestyle Migration: The Discursive Construction of 'Glocal' Place-Identity. Mobilities, 7(1), 71-92.

Uriely, N., 2001. 'Travelling Workers' and 'Working Tourists': Variations Across the Interaction between Work and Tourism. International Journal of Tourism Research, 3(1), 18.

Urry, J., 2002. 'Mobility and proximity'. Sociology, 36(2), 255-274.

Veijola, S., 2009. 'Introduction: Tourism as Work'. Tourist Studies, 9(2), 83-87.

Walsh, K., 2006. 'Dad says I'm tied to a shooting star!" Grounding (research on) British expatriate belonging. Area, 38(3), 268-278.

Warde, A. and Martens, L., 1998. 'Food choice: a sociological approach' In: A. Murcott, ed. The Nation's Diet. London: Longman, 129-146.

White, N.R. and White, P.B., 2004. Travel as Transition: Identity and Place. Annals of Tourism Research, 31(1), 200-218.

White, N.R. and White, P.B., 2007. Home and away: Tourists in a Connected World. Annals of Tourism Research, 34(1), 88-104.

Williams, A.M. and Hall, C.M., 2000. Tourism and Migration: New Relationships between Production and Consumption. Tourism Geographies, 2(1), 5-27.

Williams, R. D. and McIntyre, N., 2001. Where Heart and Home Reside: Changing Constructions of Place and Identity. In: Trends2000: Shaping the Future. Lansing: Michigan State University, 392-403.

Wilson, J., Fisher, D. and Moore, K., 2009. The OE Goes 'Home': Cultural Aspects of a Working Holiday Experience. Tourist Studies, 9(3), 3-21.

Zampoukos, K. and Ioannides, D., 2011. The Tourism Labour Conundrum: Agenda for New Research in the Geography of Hospitality Workers. Hospitality and Society, 1(1), 25-45. 